\title{
Synthesis of Diamides and Diimines Derived from 4,4'-(1,3-Phenylenebis(oxy))dianiline, Units for Symmetrical Macrocycles
}

\author{
Said Nadeem, ${ }^{1}$ Muhammad R. Shah, ${ }^{1}$ Kiramat Shah, ${ }^{1}$ \\ Akhtar Mohammad, ${ }^{2}$ and Burhan Khan ${ }^{1}$ \\ ${ }^{1}$ HEJ Research Institute of Chemistry, International Center for Chemical and Biological Sciences, University of Karachi, \\ Karachi 75270, Pakistan \\ ${ }^{2}$ Chemistry Department, University of Karachi, Karachi 75270, Pakistan
}

Correspondence should be addressed to Said Nadeem, said81nadeem@yahoo.com

Received 11 August 2012; Revised 6 November 2012; Accepted 7 November 2012

Academic Editor: Ashraf Aly Shehata

Copyright (C) 2012 Said Nadeem et al. This is an open access article distributed under the Creative Commons Attribution License, which permits unrestricted use, distribution, and reproduction in any medium, provided the original work is properly cited.

4, $4^{\prime}$-(1,3-Phenylenebis(oxy))dianiline $\mathbf{1}$ is an aromatic diamine compound and has been very less utilized in the organic synthesis. Different diimines and diamides were synthesized by reacting compound $\mathbf{1}$ with aromatic and heterocyclic compounds having different functionalities. These longer electron rich spacer molecules were synthesized to utilize them in the near future in making macrocycles of different sizes and functionalities. A hydrazide was also prepared from a diamide spacer molecule containing ester group. A diamide prepared containing nibrobenzene moiety was further reduced to amine to obtain longer spacer diamine molecule than the starting molecule $\mathbf{1}$.

\section{Introduction}

The condensation of primary amines with carbonyl group was discovered in 1864 by Schiff [1] and has been always the reaction of interest to chemists up to date in the fields of macrocyclic and supramolecular chemistry. The more interesting case is the cyclization of dicarbonyl compounds with diamines which can produce verity of products like $[1+1]$ condensation, $[2+1]$-condensation or [1+2]-condensation products, and so forth. These types of reactions lead to macrocylization after $[2+2]$-condensation occurs.

The functionally substituted Schiff bases bearing additional donor groups represent the most important class of heteropolydentate ligands in coordination chemistry which can form mono-, bi-, and polynuclear complexes with different transition and nontransition metals. Interest in exploring metal ion complexes with macrocyclic ligands has been continuously increasing owing to the recognition of the role played by these structures in metalloproteins [2]. When synthesizing macrocycles from these unit molecules being reported, metal ions with different ionic radii and coordination requirements can control the structure and size of the macrocycle [3]. The literature is full of books and reviews devoted to template synthesis of the macrocyclic Schiff-base complexes and their properties [4-10]. Gerbeleu et al. analyzed in detail the template synthesis of macrocyclic systems [11] while other reviews of Vigato and coworkers are most comprehensive $[12,13]$. Another review focusing on chemistry of pyrrole-containing macrocyclic Schiff bases was published by Callaway et al. [14] .

Leading towards different topologically important macrocycles, two different types of macrocycles were the targets. These macrocycles can be electron donors, that is, macrocycles having electron rich heteroatoms and having the donating power to catch or cage the cation inside the ring which can be also used as artificial ion channel for cations in the future. The second type is the acceptor macrocycles, which has electron deficient species and can cage or catch the anions inside the ring or may act as artificial channels for anions. Keeping in mind the aforementioned properties, 
different units were synthesized which will lead to these macrocycles. Mainly the three phenyl longer compound $4,4^{\prime}$ (1,3-phenylenebis(oxy))dianiline $\mathbf{1}$ (Figure 1) was used to synthesize these units having hydrogen bonding interactions.

The molecule $\mathbf{1}$ is a diamine, electron rich, dinucleophile, easily reacts with acyl halides, aldehyde, and other groups containing electrophilic carbons or good leaving groups. Different units synthesized from $\mathbf{1}$ and some other molecules are described below.

For the synthesis of donor macrocycles, many units were synthesized which can be used as electrophiles or nucleophile. These groups will be used in different combinations to make macrocycles. These units can be divided into three subgroups according to the functional groups they have, for example, amides, imines, and other units.

\section{Result and Discussion}

2.1. Amide Units. Different units containing amide bond were synthesized by reacting acyl halides and esters with diamine $\mathbf{1}$. Amide units synthesized from acyl chlorides were easy to give amide containing compounds as compared to esters. In a typical reaction, 2.2 molar benzoyl chloride 2 was added dropwise at $0^{\circ} \mathrm{C}$ to 1 molar diamine 1 solution in dichloromethane in the presence of dry potassium carbonate and stirred until the reaction mixture reached to room temperature. Precipitates were started to develop after the mixture was poured in distilled water which were filtered, and washed with excess of water to remove acids and potassium carbonate. The crude compound 3 was dried in vacuum and characterized through for NMR and other analytical techniques. A general reaction of amide unit formation is given in Scheme 1.

The ${ }^{1} \mathrm{H}$ NMR showed all the peaks in the spectrum which were expected. The spectrum showed a doublet of doublet at $\delta 7.86$ of four protons, a singlet of two protons at $\delta 7.83$, a doublet of doublet at $\delta 7.6$ of four protons, a doublet of doublet at $\delta 7.53$ of two protons, a doublet of doublet at $\delta 7.49$ of four protons, a triplet of one proton at $\delta 7.45$, a doublet of four protons at $\delta 7.05$, a doublet of doublet of two protons at $\delta 6.72$, and a triplet of one proton at $\delta 6.62$. The UV-visible spectrum was recorded of the product in DMSO and three $\lambda_{\max }$ peaks were observed at 202, 224, and $275 \mathrm{~nm}$ with absorbence of $1.51,0.5$, and 0.5 , respectively. IR was recorded in $\mathrm{KBr}$ disc and the main stretchings observed were 3293 broad, 1646, 1511, 1215, and $693 \mathrm{vcm}^{-1}$.

Some amides were also synthesized from esters by refluxing esters in methanol with the diamine 1 . In a model example, an excess amount of di-tert-butyl oxalate 4 was refluxed in a methanol with 1 and the reaction progress was monitored with TLC. It took approximately 36 hours to complete the reaction. The crude mixture was purified through column chromatography and the product 5 was analyzed through NMR and EI-MS. The reaction is represented in Scheme 2.

The ${ }^{1} \mathrm{H}$ NMR of the product was obtained in deuterated chloroform. The peaks observed in the spectrum are a singlet of two protons at $\delta 9.96$, a doublet of four protons at $\delta$
7.95 , a triplet of one proton at $\delta 7.72$, a doublet of four protons at $\delta 7.62$, a triplet of one proton at $\delta 7.2$, a doublet of doublet of two protons at $\delta 6.5$, and a singlet of 18 protons belongs to butyl group at $\delta 1.23$. The UV-visible spectrum was obtained in chloroform and the $\lambda_{\max }$ in the spectrum were observed at 227 and $242 \mathrm{~nm}$ with absorbencies of 3.927 and 4.0, respectively. The IR spectrum was obtained in $\mathrm{KBr}$ disc and the main stretching bands observed were 3727, 2921, $1679,1587,1424,755$, and $675 v \mathrm{~cm}^{-1}$.

Mainly the amides synthesized from acyl chlorides were obtained in good yield and were pure enough for NMR and no need was felt for purification by chromatography. According to the same procedures described for the synthesis of amide units for macrocycles, other amide units were synthesized which can be used for the synthesis of hydrogen bonding macrocycles directly or after certain reaction(s). Figure 2 shows the examples of amides $(\mathbf{3}, \mathbf{5}-\mathbf{9})$ synthesized from the diamine 1 .

All of the above amide units are important for the synthesis of macrocycles which would be having hydrogen bonding properties. Compound $\mathbf{3}$ has only phenyl rings as benzoyl chloride was used to synthesize it and optimize the reaction conditions and to solve the solubility problems. Compound 6 has $-\mathrm{OCH}_{3}$ groups which can be demethylated by using $\mathrm{BBr}_{3}$ to obtain $-\mathrm{OH}$ groups. These $-\mathrm{OH}$ groups can be further utilized to attach with other longer units having electrophiles, for example, 8 to obtain macrocycles having propyl amide ethers. Compound $\mathbf{8}$ can also be used to synthesize macrocycles by reacting it with other dinucleophiles to obtain symmetrical and asymmetrical macrocycles. 5 and $\mathbf{9}$ are both diketones with amide and ester groups but 5 has a bulky butyl group and can be used at high temperature to induce selectivity while $\mathbf{9}$ is simple methoxy ester and easily convertible to amides or thioesters, and so forth.

Compound 7 has $-\mathrm{NO}_{2}$ functional groups which cannot be utilized as nucleophiles for the synthesis of macrocycles. The nitro group of the diamide 7 was reduced to obtain again diamine 10 with longer length and with more flexibility and degrees of freedom. Compound 7 was refluxed in acidic ethanol in the presence of Tin(II) chloride as shown in Scheme 3.

After completion of the reaction, the product was poured in distilled water and neutralized to $\mathrm{pH}$ 7. The precipitates formed were filtered and washed further with distilled water. The crude product was purified on column chromatography by using chloroform and methanol as eluent. The product was analyzed by NMR and EI-MS which confirm the formation of the reduced product 1 .

As $\mathbf{5}$ and $\mathbf{9}$ are both electrophilic for the synthesis of macrocycles and having esters functionalities. They can be easily converted to hydrazides by reacting it with hydrazine, so they will be acting like nucleophiles for the synthesis of macrocycles and also with more hydrogen bonding properties. The synthesis of dihydrazide 11 was achieved with the help of $\mathbf{5}$ and $\mathbf{9}$. Reactant ester was taken in a test tube and stirred at $0^{\circ} \mathrm{C}$ for 10 minutes in hydrazine as shown in Scheme 4 and allowed for ten minutes in order to get precipitates. 
<smiles>Nc1ccc(Oc2cccc(Oc3ccc(N)cc3)c2)cc1</smiles>

Figure 1: Diamine 1.<smiles>O=C(Nc1ccc(Oc2cccc(Oc3ccc(NC(=O)c4ccccc4)cc3)c2)cc1)c1ccccc1</smiles><smiles>CC(C)(C)OC(=O)C(=O)Nc1ccc(Oc2cccc(Oc3ccc(NC(=O)C(=O)OC(C)(C)C)cc3)c2)cc1</smiles>

5<smiles>COc1ccc(C(=O)Nc2ccc(Oc3cccc(Oc4ccc(NC(=O)c5ccc(OC)cc5)cc4)c3)cc2)cc1</smiles>

6<smiles>O=C(Nc1ccc(Oc2cccc(Oc3ccc(NC(=O)c4ccc([N+](=O)[O-])cc4)cc3)c2)cc1)c1ccc([N+](=O)[O-])cc1</smiles><smiles>O=C(CCCCl)Nc1ccc(Oc2cccc(Oc3ccc(NC(=O)CCCCl)cc3)c2)cc1</smiles>

8<smiles>COC(=O)C(=O)Nc1ccc(Oc2cccc(Oc3ccc(NC(=O)C(=O)OC)cc3)c2)cc1</smiles>

Figure 2: Different diamide units from diamine 1. 
(O)<smiles>COc1cccc(/C=N/c2ccc(Oc3cccc(Oc4ccc(/N=C/c5cccc(OC)c5OC)cc4)c3)cc2)c1OC</smiles><smiles>Brc1ccc(/C=N/c2ccc(Oc3cccc(Oc4ccc(/N=C/c5ccc(Br)cc5)cc4)c3)cc2)cc1</smiles><smiles>C(=N/c1ccc(Oc2cccc(Oc3ccc(/N=C/c4ccncc4)cc3)c2)cc1)\c1ccncc1</smiles><smiles>COc1ccc(/C=N/c2ccc(Oc3cccc(Oc4ccc(/N=C/c5ccc(OC)cc5)cc4)c3)cc2)cc1</smiles><smiles>C(=N/c1ccc(Oc2cccc(Oc3ccc(/N=C/c4cccnc4)cc3)c2)cc1)\c1cccnc1</smiles><smiles>COc1ccc(/C=N/c2ccc(Oc3cccc(Oc4ccc(/N=C/c5ccc(OC)c(OC)c5OC)cc4)c3)cc2)c(/C=N/c2ccc(Oc3cccc(Oc4ccc(/N=C/c5ccc([N+](=O)[O-])cc5)cc4)c3)cc2)c1</smiles>

Figure 3: Different diimine units from diamine 1. 


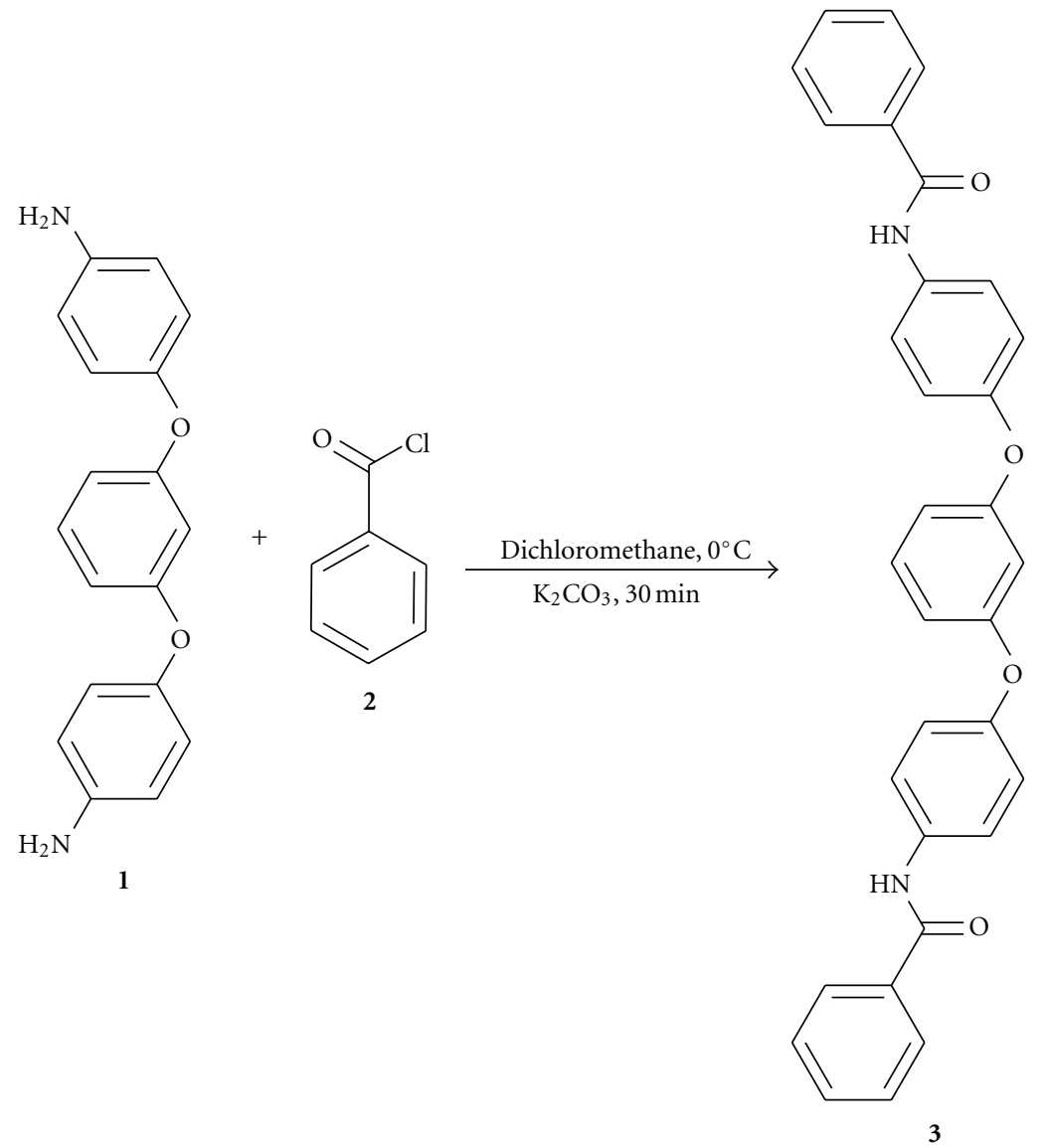

Scheme 1: Synthesis of spacer diamide unit from acyl chloride.

White pasty precipitates were obtained, which were filtered and washed with cold distilled water to remove extra hydrazine. The crude product was obtained as white jelly, which solidified after two days to form a white solid.

The compound was characterized through for ${ }^{1} \mathrm{H}$ NMR in dimethyl sulfoxide and showed two singlet of two protons at $\delta 10.6$ and 10.2, two doublets of four protons at $\delta 7.8$ and 7.0 , two triplets, each of one proton at $\delta 7.3$ and 6.5 , a doublet of doublet of two protons at $\delta 6.6$, and a broad peak of four protons at $\delta$ 4.6. The UV-visible spectrum was recorded in DMSO and two $\lambda_{\max }$ peaks were observed at 380 and $330 \mathrm{~nm}$ having absorbencies of 1.56 and 0.28 . The IR in $\mathrm{KBr}$ was also obtained and the main stretchings were 3284, 1658, 1513, 1217 , and $541 v \mathrm{~cm}^{-1}$.

2.2. Imine Units. After synthesizing the longer units for the synthesis of macrocycles having hydrogen bonding properties, another motif (imine) was selected, this could impart unsaturation and conjugation to the macrocycles. Similar to these motifs (imine) also provide suitable functional group for electrophilic substitution reaction. The starting molecule $\mathbf{1}$ is a diamine and it would be very easy to react it with aldehydes to obtain imine units. As imines are also having good interactions for hydrogen bonding, these imine units could be directly utilized for the synthesis of macrocycles or can be reduced in the next step to secondary amines. Both imine and amine containing macrocycles are important for the preparation of nanotubes because of their supramolecular interactions of $\mathrm{N}-\mathrm{H}-\mathrm{N}$ bonds.

In a typical reaction, the diamine $\mathbf{1}$ was condensed with benzaldehyde 12 in dichloromethane at room temperature to form imine 13 as shown in Scheme 5.

The reaction was completed in one hour. The solvent was evaporated and yellow crystalline material was obtained which was purified by recrystallization from ethanol. The product 13 was characterized through ${ }^{1} \mathrm{H}$ NMR and EI-MS to confirm the product formation. The ${ }^{1} \mathrm{H}$ NMR showed a sharp singlet showing the presence of imine proton, and also the IR spectra showed $\mathrm{C}=\mathrm{N}$ stretching and bending peaks.

Other longer imine units were synthesized which would be used directly or after reducing for the synthesis of longer units and macrocycles. The imine units (13-20) synthesized from diamine $\mathbf{1}$ are shown in Figure 3.

The product 13 was obtained in one hour at room temperature in DCM. The $\mathbf{1 3}$ was selected for further condensation with aldehyde and ketone to induce further spacer elongation. The imines having one or more $-\mathrm{OCH}_{3}$ groups, for example, 17, 14, and 20 can be first reduced to secondary amines and then demethylate by using $\mathrm{BBr}_{3}$ in dichloromethane to obtain -OH groups. These units would be 


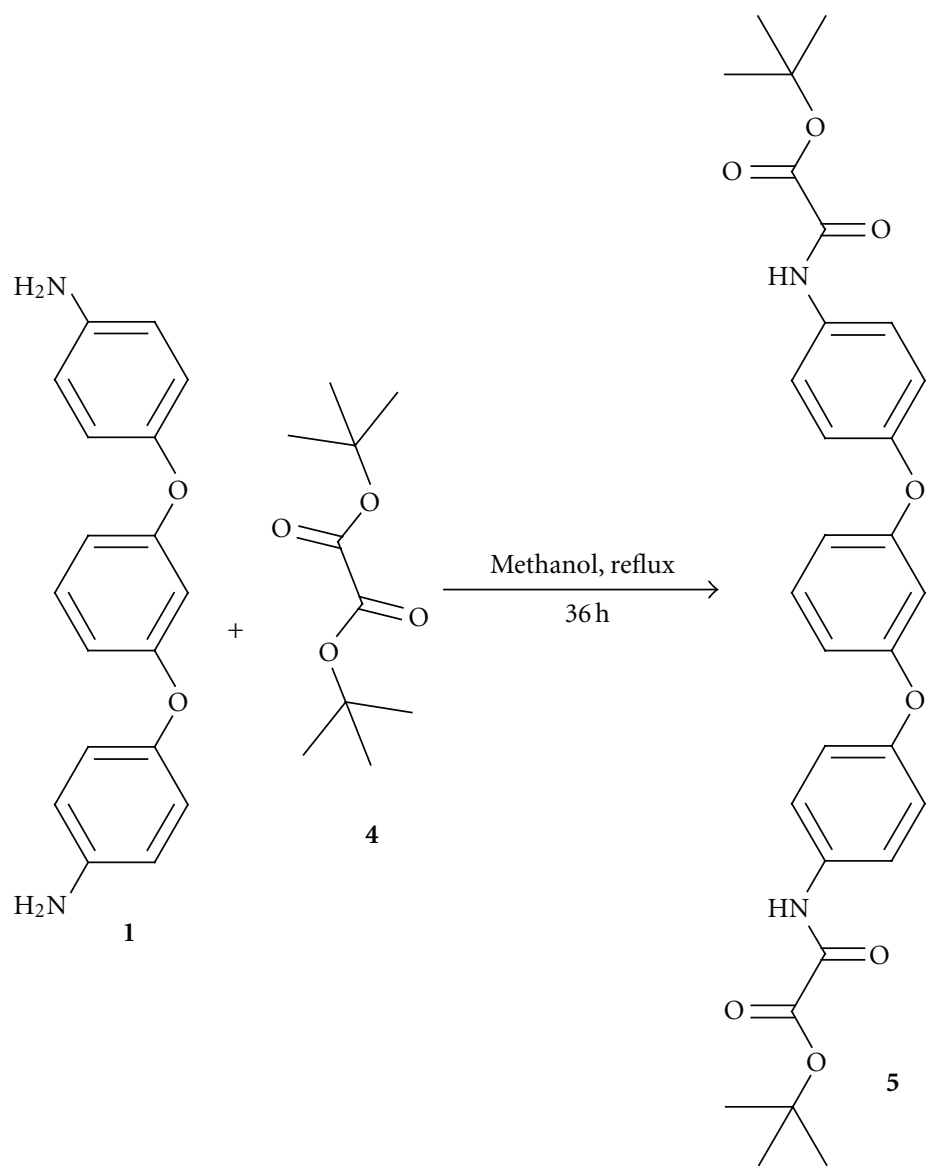

Scheme 2: Synthesis of spacer diamide unit from esters.

having both $\mathrm{R}-\mathrm{NH}-\mathrm{R}$ and -OH groups which would be used for introduction of functional groups or substitutions. The bromo-derivative imine unit $\mathbf{1 5}$ is suitable for Sonogashira coupling reaction [15] for the synthesis of macrocycle which would be having properties of acetylene and imine (or amine if reduced before Sonogashira coupling reaction). The imine unit 19 has $-\mathrm{NO}_{2}$ group which can be reduced to $-\mathrm{NH}_{2}$ groups and further longer chains would be obtained having nucleophilic properties of amines, which could be reacted with ester amine 9 synthesized before to obtain macrocycles having different properties.

Most of these imine units synthesized were obtained in the form of yellow crystalline material, so the $-\mathrm{OCH}_{3}$ imine unit $\mathbf{1 7}$ was subjected to X-ray crystallography and nice crystallographic structure was obtained from the study which was also a source of confirmation of the product [16].

Most of the above synthesized units are electron rich and would be used in the synthesis of electron rich macrocycles. Certain imine units were also synthesized which would be used in the future for the synthesis of electron rich macrocycles, for example, $\mathbf{1 6}$ and 18. These two imine units consist of pyridine rings which could be easily used as nucleophile and will result electron deficient macrocycles which would attract any electron rich molecule towards its center because of the supramolecular attractions.

\section{Experimental}

All the reactions were performed according to standard methods with clean glassware and from commercial chemicals which were ultrapure. The work up of different reactions was performed by different procedures according to the need and type of reaction. Compounds were purified by column chromatography using column and flash silica, and recrystallization with different solvents. Some reactions are same except the chemicals reacted, so instead writing all of them, a model reaction will be written. Characterization of pure compounds was done by different techniques including Mass Spectrometric techniques, that is, EIMS (JEOL JMS600), $\mathrm{FAB}+, \mathrm{FAB}-;{ }^{1} \mathrm{HNMR}$ (Bruker Avance 400, Avance AV 300), UV (SECOMAM, ANTHJRPC V. $4.1 \mathrm{~h}$ ), IR (VECTOR22), and TLC. The procedures of the compounds synthesized are given below.

$N, N^{\prime}-\left(4,4^{\prime}-(1,3-p h e n y l e n e b i s(\right.$ oxy $))$ bis(4,1-phenylene $\left.)\right)$ bis(4chlorobutanamide) (8). A representative reaction for amide synthesis is given here for $\mathbf{8}$, otherwise the difference in procedure is given in the experimental if any. $100 \mathrm{mg}$ $(0.342 \mathrm{mmol})$ of $4,4^{\prime}$-(1,3-phenylenebis(oxy))dianiline $\mathbf{1}$ was dissolved in $2 \mathrm{~mL}$ dichloromethane in a dry test tube with stirring and cold at $0^{\circ} \mathrm{C} . \mathrm{K}_{2} \mathrm{CO}_{3}$ was added to neutralize 


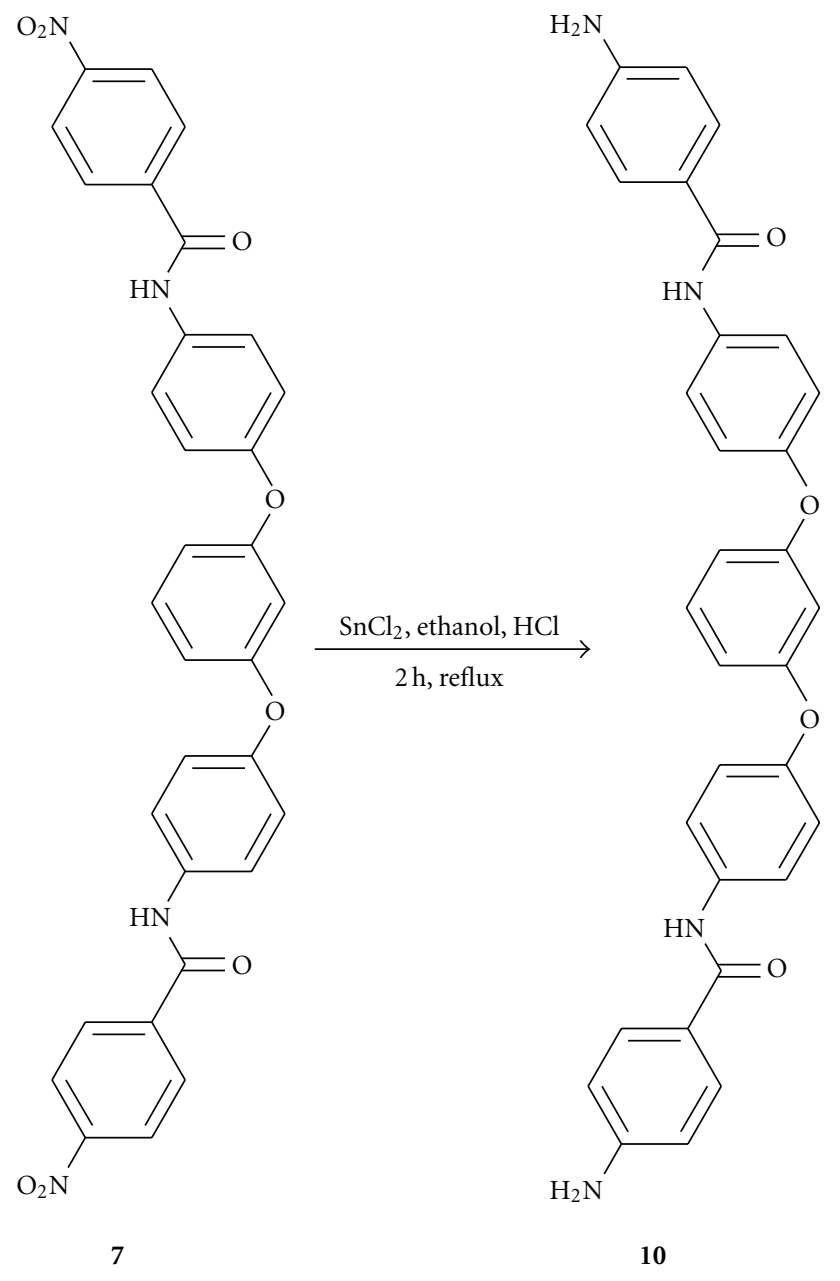

Scheme 3: Reduction of diamide-nitro unit to diamide-amine spacer molecule.

$\mathrm{HCl}$. Few drops of 4-chlorobutanoyl chloride were added in portions to reaction mixture. At room temperature, the reaction mixture was poured in distilled water. The desired compound $\mathbf{8}$ was precipitated in water. The target molecule was filtered and washed with distilled water and dried, obtained as cream color solid. EIMS $\mathrm{m} / \mathrm{z}: 501 ;{ }^{1} \mathrm{H}$ NMR $400 \mathrm{MHz}, \mathrm{DMSO}_{\mathrm{d}} \delta$ (ppm): 9.99 (s, 2H), $7.61(\mathrm{~d}, 4 \mathrm{H}, J=$ $8.7 \mathrm{~Hz}), 7.29(\mathrm{t}, 1 \mathrm{H}, J=8.1 \mathrm{~Hz}), 7.01(\mathrm{~d}, 4 \mathrm{H}, J=8.7 \mathrm{~Hz}), 6.6$ $(\mathrm{dd}, 2 \mathrm{H}, 4 J=2.4 \mathrm{~Hz}, 3 J=8.4 \mathrm{~Hz}), 6.5(\mathrm{t}, 1 \mathrm{H}, 4 J=2.1 \mathrm{~Hz})$, $3.67(\mathrm{t}, 4 \mathrm{H}, J=6.6 \mathrm{~Hz}), 2.46(\mathrm{t}, 4 \mathrm{H}, J=7.2 \mathrm{~Hz}), 2.02$ (quint, $4 \mathrm{H}, J=6.9 \mathrm{~Hz}$ ); UV DMSO $\lambda_{\max } \mathrm{nm}$ (abs): 271 (1.68); IR $\mathrm{KBr} v \mathrm{~cm}^{-1}: 3291,1656,1512,1228,851$; Anal. Calculated $\mathrm{C}_{26} \mathrm{H}_{26} \mathrm{Cl}_{2} \mathrm{~N}_{2} \mathrm{O}_{4}$ (501.40): C, 62.28; H, 5.23; N, 5.59; found: C, 63.561; H, 3.701; N, 6.137.

$N, N^{\prime}$-(4,4'-(1,3-phenylenebis(oxy))bis(4,1-phenylene))dibenzamide (3). Benzoly chloride was added according to the previous procedures, and the desired compound was obtained as white solid, purified using ethanol as eluent in column chromatography, obtained as white crystals; EIMS $m / z: 500 ;{ }^{1} \mathrm{H}$ NMR $400 \mathrm{MHz}, \mathrm{CDCl}_{3} \delta(\mathrm{ppm}): 7.86(\mathrm{~d}$, $4 \mathrm{H}, J=8.4 \mathrm{~Hz}), 7.78(\mathrm{~s}, 2 \mathrm{H},-\mathrm{NH}), 7.60(\mathrm{~d}, 4 \mathrm{H}, J=8.90 \mathrm{~Hz})$, $7.53(\mathrm{~d}, 2 \mathrm{H}, J=7.1 \mathrm{~Hz}), 7.49(\mathrm{~d}, 4 \mathrm{H}, J=7.5 \mathrm{~Hz}), 7.45(\mathrm{t}$, $1 \mathrm{H}), 7.05(\mathrm{~d}, 4 \mathrm{H}, J=8.88 \mathrm{~Hz}), 6.72(\mathrm{dd}, 2 \mathrm{H}, 4 J=2.31 \mathrm{~Hz}$, $3 J=8.22 \mathrm{~Hz}), 6.62(\mathrm{t}, 1 \mathrm{H}, J=2.26 \mathrm{~Hz})$; UV DMSO $\lambda_{\max } \mathrm{nm}$ (abs): 202 (1.53), 224 (0.5), 275 (0.5); IR KBr $v \mathrm{~cm}^{-1}: 3293$ broad, 1646, 1511, 1215, 693 .

t-Butyl-2,2'-(4,4'-(1,3-phenylenebis(oxy))bis(4,1-phenylene)) bis(azanediyl)bis(2-oxoacetate) (5). $100 \mathrm{mg}$ of 1 was dissolved in $3 \mathrm{~mL}$ methanol di-t-butyl oxalate was added in excess, and refluxed for 36 hours, evaporated and purified by ethanol as eluent in column chromatography, obtained as brownish solid; EIMS m/z: 548; ${ }^{1} \mathrm{H}$ NMR $400 \mathrm{MHz}, \mathrm{CDCl}_{3} \delta$ (ppm): $9.96(\mathrm{~s}, 2 \mathrm{H},-\mathrm{NH}), 7.95(\mathrm{~d}, 4 \mathrm{H}, J=8.45 \mathrm{~Hz}), 7.72(\mathrm{t}$, $1 \mathrm{H}, J=10.7 \mathrm{~Hz}), 7.62(\mathrm{~d}, 4 \mathrm{H}, J=8.48 \mathrm{~Hz}), 7.2(\mathrm{t}, 1 \mathrm{H}), 6.5$ dd $(2 \mathrm{H}), 1.64$ (br, s, $18 \mathrm{H})$; UV $\mathrm{CDCl}_{3} \lambda_{\max } \mathrm{nm}$ (abs): 227 (3.927), 242 (4.0); IR KBr $v \mathrm{~cm}^{-1}: 3727,2921,1679,1587$, $1424,755,675$.

$N, N^{\prime}-\left(4,4^{\prime}-(1,3-p h e n y l e n e b i s(o x y)) b i s(4,1-p h e n y l e n e)\right) b i s(4-$ methoxybenzamide) (6). The desired compound was obtained by the coupling of $\mathbf{1}$ and anisoyl chloride according to earlier procedure; EIMS m/z: 560; ${ }^{1} \mathrm{H}$ NMR $400 \mathrm{MHz}$, 


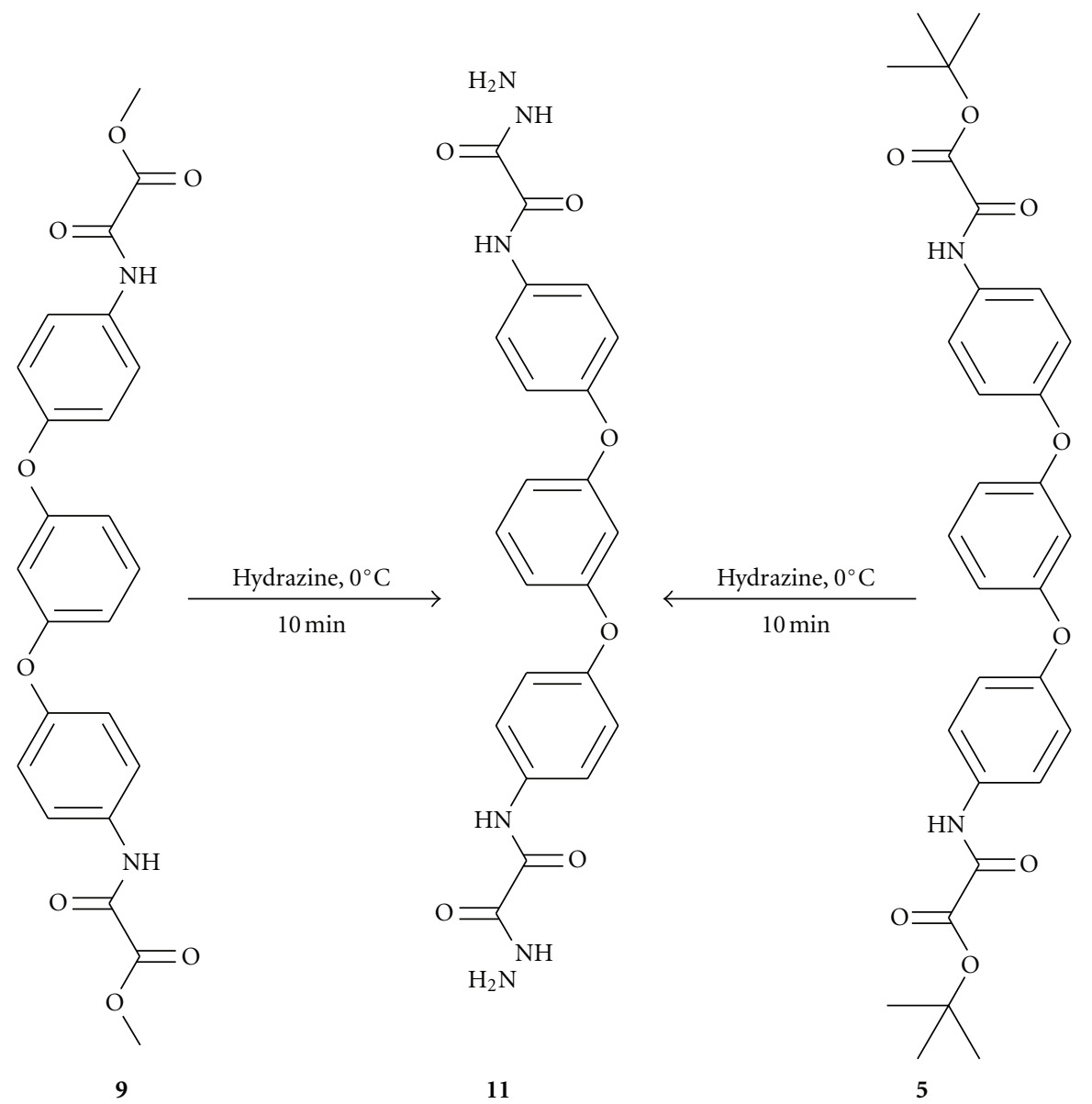

Scheme 4: Synthesis of dihydrazide from esters 9 and $\mathbf{5 .}$

$\mathrm{DMSO}_{\mathrm{d}} \delta(\mathrm{ppm}): 10.11(\mathrm{~s}, 2 \mathrm{H},-\mathrm{NH}), 7.95(\mathrm{~d}, 4 \mathrm{H}, J=$ $8.63 \mathrm{~Hz}), 7.89(\mathrm{~d}, 4 \mathrm{H}, J=8.69 \mathrm{~Hz}), 7.79(\mathrm{~d}, 4 \mathrm{H}, J=8.86 \mathrm{~Hz})$, $7.3(\mathrm{t}, 1 \mathrm{H}, J=8.20 \mathrm{~Hz}), 6.99(\mathrm{~d}, 4 \mathrm{H}, J=8.7 \mathrm{~Hz}), 6.69(\mathrm{dd}$, $2 \mathrm{H}, 4 J=2.00 \mathrm{~Hz}, 3 J=8.22 \mathrm{~Hz}), 6.5(\mathrm{t}, 1 \mathrm{H}), 3.83(\mathrm{~d}, 6 \mathrm{H}$, $J=4.29 \mathrm{~Hz}$ ); UV DMSO $\lambda_{\max } \mathrm{nm}$ (abs): 274 (1.87), 203 (0.262); IR KBr $v \mathrm{~cm}^{-1}$ : 3329 broad, 3419, 2840, 1650, 1604, 1508, 1258, 838; Anal. Calculated for: $\mathrm{C}_{34} \mathrm{H}_{28} \mathrm{~N}_{2} \mathrm{O}_{6}$ (560.60), Elemental Analysis: C, 72.84: H, 5.03: N, 5.00: O, 17.12, Found: C, 64.50: H, 4.95: N, 4.836.

$N, N^{\prime}-\left(4,4^{\prime}-(1,3-p h e n y l e n e b i s(o x y)) b i s(4,1-p h e n y l e n e)\right) b i s(4-$ nitrobenzamide) (7). To a cooled solution of $\mathbf{1}$ in dichloromethane, 4-nitrobenzoyl chloride was added dropwise, yellow solid was obtained, purified by column chromatography using hexane and ethyl acetate as eluent, obtained as bright yellow solid; EIMS $m / z$ : 590; ${ }^{1} \mathrm{H}$ NMR $400 \mathrm{MHz}, \mathrm{DMSO}_{\mathrm{d}} \delta(\mathrm{ppm}): 10.60(\mathrm{~s}, 2 \mathrm{H},-\mathrm{NH}), 8.37$ (d, $4 \mathrm{H}, J=8.69 \mathrm{~Hz}), 8.18(\mathrm{~d}, 4 \mathrm{H}, J=8.68 \mathrm{~Hz}), 7.81(\mathrm{~d}, 4 \mathrm{H}$, $J=8.85 \mathrm{~Hz}), 7.35(\mathrm{t}, 1 \mathrm{H}, J=8.12 \mathrm{~Hz}), 7.11(\mathrm{~d}, 4 \mathrm{H}, J=$ $8.92 \mathrm{~Hz}), 6.73(\mathrm{dd}, 2 \mathrm{H}, 4 J=2.2 \mathrm{~Hz}, 3 J=8.15 \mathrm{~Hz}), 6.58(\mathrm{t}$, $1 \mathrm{H}, J=2.07 \mathrm{~Hz}$ ); UV DMSO $\lambda_{\max } \mathrm{nm}$ (abs): 203 (2.613), 255 (2.105); IR KBr $v \mathrm{~cm}^{-1}: 3777,3698,3319$ broad, 3115, 2879, 2828, 1814. 1762, 1718, 15911322, 712; Anal. Calculated:
$\mathrm{C}_{32} \mathrm{H}_{22} \mathrm{~N}_{4} \mathrm{O}_{8}$ (590.54): C, 65.08; H, 3.75; N, 9.49; O, 21.67; found: C, $54.665 ; \mathrm{H}, 3.625 ; \mathrm{N}, 8.216$.

Dimethyl-2,2' - (4,4' - (1,3-phenylenebis(oxy))bis(4,1-phenylene)) bis(azanediyl)bis(2-oxoacetate) (9). Few drops of methyl 2-chloro-2-oxoacetate were added to 1 , and desired compound was obtained as white solid according to the earlier procedure; EIMS $m / z: 464 ;{ }^{1} \mathrm{H}$ NMR $400 \mathrm{MHz}$, $\mathrm{DMSO}_{\mathrm{d}} \delta(\mathrm{ppm}): 10.85(\mathrm{~s}, 2 \mathrm{H}), 7.77(\mathrm{~d}, 4 \mathrm{H}, J=9.2 \mathrm{~Hz}), 7.3$ $(\mathrm{t}, 1 \mathrm{H}, J=8.4 \mathrm{~Hz}), 7.08(\mathrm{~d}, 4 \mathrm{H}, J=8.8 \mathrm{~Hz}), 6.70(\mathrm{dd}, 2 \mathrm{H}, 4 J$ $=2.4 \mathrm{~Hz}, 3 \mathrm{~J}=8.4 \mathrm{~Hz}), 6.5(\mathrm{t}, 1 \mathrm{H}, J=2.4 \mathrm{~Hz}), 3.84(\mathrm{~s}, 6 \mathrm{H}$, $\left.-\mathrm{OCH}_{3}\right)$; UV DMSO $\lambda_{\max } \mathrm{nm}$ (abs): 288; IR $\mathrm{KBr} v \mathrm{~cm}^{-1}$ : 3336, 1694, 1543, 1214, 853, 690, 494; Anal. Calculated: $\mathrm{C}_{24} \mathrm{H}_{20} \mathrm{~N}_{2} \mathrm{O}_{8}$ (464.42); C, 62.07; H, 4.34; N, 6.03; O, 27.56; found: C, 62.933; H, 4.346; N, 6.238.

$N, N^{\prime}-\left(4,4^{\prime}-(1,3-p h e n y l e n e b i s\right.$ (oxy))bis(4,1-phenylene))bis(4aminobenzamide) (10). $100 \mathrm{mg} 7$ was taken in $4 \mathrm{~mL}$ of ethanol and $250 \mathrm{mg} \mathrm{SnCl} 2$ was added. Few drops of concentrated $\mathrm{HCl}$ were also added. Refluxed for 4 hours and poured in $100 \mathrm{~mL}$ of distilled water. Extracted with ethyl acetate and obtained as brown solid, purified on column chromatography using 1:1 chloroform: methanol as eluent; EIMS $\mathrm{m} / \mathrm{z}$ : 


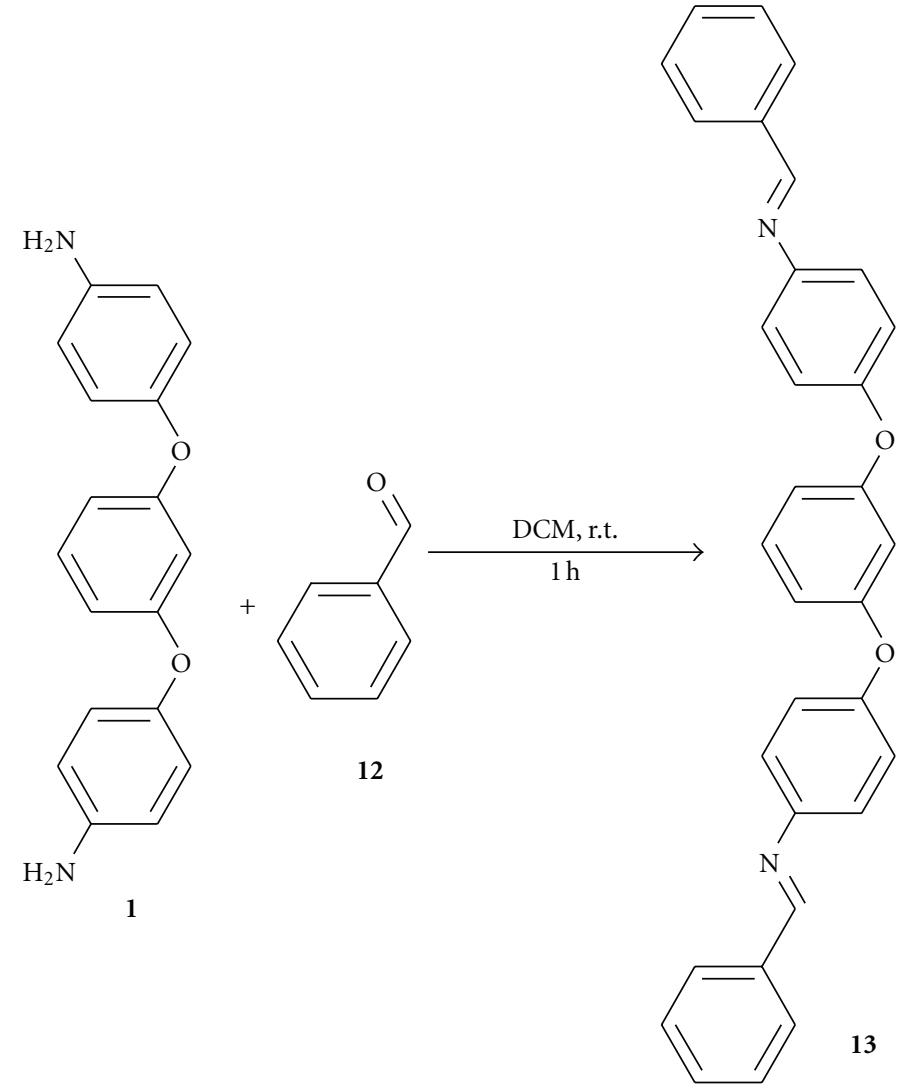

Scheme 5: Synthesis of diimine unit from benzaldehyde.

530; ${ }^{1} \mathrm{H}$ NMR $400 \mathrm{MHz}, \mathrm{CDCl}_{3} \delta(\mathrm{ppm}): 8.1(\mathrm{~s}, 2 \mathrm{H},-\mathrm{NH})$, $7.70(\mathrm{~d}, 4 \mathrm{H}, J=8.51 \mathrm{~Hz}), 7.67(\mathrm{~d}, 4 \mathrm{H}, J=7.9 \mathrm{~Hz}), 7.57(\mathrm{~d}$, $4 \mathrm{H}, J=8.83 \mathrm{~Hz}), 7.19(\mathrm{t}, 1 \mathrm{H}), 7.03(\mathrm{~d}, 4 \mathrm{H}, J=8.82 \mathrm{~Hz}), 6.70$ $(\mathrm{dd}, 2 \mathrm{H}, J=4.07 \mathrm{~Hz}), 6.60(\mathrm{t}, 1 \mathrm{H}, J=2.52 \mathrm{~Hz}), 4.00(\mathrm{~s}, 4 \mathrm{H},-$ $\mathrm{NH}_{2}$ ); UV CDCl $\lambda_{3} \lambda_{\max } \mathrm{nm}$ (abs): 203 (1.55), 300 (0.979); IR $\mathrm{KBr} v \mathrm{~cm}^{-1}: 3780,3697,3464,3349$ broad, 2922, 2854, 1725, $1600,1262,1210,1117,838,677$.

$N, N^{\prime}-\left(4,4^{\prime}-(1,3-p h e n y l e n e b i s(o x y)) b i s(4,1-p h e n y l e n e)\right) b i s(2-$ hydrazinyl-2-oxoacetamide) (11). $100 \mathrm{mg}$ of 9/5 was taken in a test tube and stirred at $0^{\circ} \mathrm{C}$ for 10 minutes in hydrazine, a white paste was obtained, which was filtered washed with cooled distilled water to remove extra hydrazine, dried and obtained as white jelly, which was solidified after two days in the form of a white solid; EIMS $m / z$ : $464 ;{ }^{1} \mathrm{H}$ NMR $400 \mathrm{MHz}$, $\mathrm{DMSO}_{\mathrm{d}} \delta$ (ppm): 10.64 (s, 2H, -NH-), 10.25 (br, s, 2H, $-\mathrm{NH}-), 7.84(\mathrm{~d}, 4 \mathrm{H}, J=9 \mathrm{~Hz}), 7.32(\mathrm{t}, 1 \mathrm{H}, J=8.4 \mathrm{~Hz}), 7.06$ $(\mathrm{d}, 4 \mathrm{H}, J=9 \mathrm{~Hz}), 6.68(\mathrm{dd}, 2 \mathrm{H}, 4 \mathrm{~J}=2.4 \mathrm{~Hz}, 3 \mathrm{~J}=8.4 \mathrm{~Hz}), 6.5$ $(\mathrm{t}, 1 \mathrm{H}, J=2.1 \mathrm{~Hz}), 4.61$ (br, s, $\left.4 \mathrm{H},-\mathrm{NH}_{2}\right)$; UV DMSO $\lambda_{\max }$ $\mathrm{nm}$ (abs): 380 (1.56), 330 (0.28); IR KBr $v \mathrm{~cm}^{-1}$ : 3284, 1658, $1513,1217,541$.

$\left(N, N^{\prime}\right)-4,4^{\prime}-(1,3-p h e n y l e n e b i s(o x y)) b i s(N$-benzylideneaniline) (13). One representative reaction of imine synthesis is given for 13, other imines were synthesized according to the same procedure, and otherwise difference is given in the experimental.
$100 \mathrm{mg}(0.342 \mathrm{mmol})$ of $4,4^{\prime}$ - (1,3-phenylenebis(oxy) ) dianiline 1 dissolved in $2 \mathrm{~mL}$ DCM in test tube, and few drops of benzaldehyde were added, stirred for 30 minutes at $35^{\circ} \mathrm{C}$. The solvent of reaction mixture was evaporated under reduced pressure and purified by column chromatography using DCM as eluent, recrystallized in DCM. White crystals were obtained in $81 \%$ yield. EIMS $\mathrm{m} / z$ : $468 ;{ }^{1} \mathrm{H} \mathrm{NMR}$ $400 \mathrm{MHz}, \mathrm{CDCl}_{3} \delta(\mathrm{ppm}): 8.46 \mathrm{~s}(2 \mathrm{H}), 7.91(\mathrm{~m}, 4 \mathrm{H}), 7.5(\mathrm{~m}$, $6 \mathrm{H}), 7.28(\mathrm{~m}, 2 \mathrm{H}), 7.2(\mathrm{~d}, 4 \mathrm{H}, J=9 \mathrm{~Hz}), 7.0(\mathrm{~d}, 4 \mathrm{H}, J=9 \mathrm{~Hz})$, 6.8 (m, 2H); UV CHCl $\lambda_{3} \lambda_{\max } \mathrm{nm}$ (abs): 250 (2.0), 308 (3.5), 350 (3.5); IR KBr $v \mathrm{~cm}^{-1}: 3408$ broad, 3061, 2876, 1623, 1585; Anal. Calculated for $\mathrm{C}_{32} \mathrm{H}_{24} \mathrm{~N}_{2} \mathrm{O}_{2}$ (468.55): C, 82.03; H, 5.16; N, 5.98; O, 6.83. Found C, 75.90; H, 5.06; N, 6.01.

$\left(N, N^{\prime}\right)-4,4^{\prime}-(1,3-p h e n y l e n e b i s(o x y))$ bis $(N-(2,3-$ dimethoxybenzylidene)aniline) (14). Obtained as brownish yellow solid and crystallized out from dichloromethane; EIMS $\mathrm{m} / \mathrm{z}$ $\mathrm{C}_{36} \mathrm{H}_{32} \mathrm{~N}_{2} \mathrm{O}_{6}: 588 ;{ }^{1} \mathrm{H}$ NMR $400 \mathrm{MHz}, \mathrm{CDCl}_{3} \delta$ (ppm): 8.85 $(\mathrm{s}, 2 \mathrm{H}), 7.73(\mathrm{~d}, 2 \mathrm{H}, J=7.8 \mathrm{~Hz}), 7.07 \mathrm{~d}(4 \mathrm{H}), 7.21 \mathrm{~d}(4 \mathrm{H})$, $7.12(\mathrm{t}, 2 \mathrm{H}, J=8.02 \mathrm{~Hz}), 7.06(\mathrm{~d}, 2 \mathrm{H}, J=8.54 \mathrm{~Hz}), 7.02(\mathrm{~d}$, $2 \mathrm{H}, J=8.19 \mathrm{~Hz}), 6.73(\mathrm{dd}, 2 \mathrm{H}, J=6.19 \mathrm{~Hz}), 6.70(\mathrm{t}, 1 \mathrm{H})$, $3.90(\mathrm{~s}, 6 \mathrm{H}), 3.89(\mathrm{~s}, 6 \mathrm{H})$.

$\left(N, N^{\prime}\right)-4,4^{\prime}$ - (1,3-phenylenebis(oxy))bis( $N$-(4-bromobenzylidene)aniline) (15). Obtained as light yellow solid and crystallized out from dichloromethane as light yellow crystals, EIMS m/z: 626; ${ }^{1} \mathrm{H}$ NMR $400 \mathrm{MHz}, \mathrm{CDCl}_{3} \delta$ 
(ppm): $8.4(\mathrm{~s}, 2 \mathrm{H}), 7.8(\mathrm{~d}, 4 \mathrm{H}, J=8.4 \mathrm{~Hz}), 7.6(\mathrm{~d}, 4 \mathrm{H}, J=$ $8.38 \mathrm{~Hz}), 7.23(\mathrm{~d}, 4 \mathrm{H}, J=8.81 \mathrm{~Hz}), 7.0(\mathrm{~d}, 4 \mathrm{H}, J=8.8 \mathrm{~Hz})$, $6.8(\mathrm{dd}, 2 \mathrm{H}, 4 \mathrm{~J}=2.19 \mathrm{~Hz}, 3 \mathrm{~J}=8.15 \mathrm{~Hz}), 6.7(\mathrm{t}, 1 \mathrm{H}, \mathrm{J}=$ $2.1 \mathrm{~Hz}$ ); UV $\mathrm{CHCl}_{3} \lambda_{\max } \mathrm{nm}$ (abs): 222 (3.87), 259 (3.7), 326 (0.6); IR KBr $v \mathrm{~cm}^{-1}$ : 3449 broad, 2873, 1680, 1616, 1586, 1496, 1237, 852, 532; Anal. Calculated for: Chemical Formula: $\mathrm{C}_{32} \mathrm{H}_{22} \mathrm{Br}_{2} \mathrm{~N}_{2} \mathrm{O}_{2}$ (626.34): C, 61.36; $\mathrm{H}, 3.54 ; \mathrm{Br}$, 25.51; N, 4.47; O, 5.11 Found C, 58.73; H, 3.541; N, 4.7.

$\left(N, N^{\prime}\right)-4,4^{\prime}-(1,3-p h e n y l e n e b i s($ oxy $)) b i s(N$ - (pyridin-4-ylmethylene) aniline) (16). Synthesized as 13, yellow crystals obtained. EIMS $m / z: 470 ;{ }^{1} \mathrm{H}$ NMR $400 \mathrm{MHz}, \mathrm{CDCl}_{3} \delta$ (ppm): $8.75(\mathrm{~d}, 4 \mathrm{H}, J=5.88 \mathrm{~Hz}), 8.46(\mathrm{~s}, 2 \mathrm{H}), 7.73(\mathrm{~d}, 4 \mathrm{H}$, $J=5.88 \mathrm{~Hz}), 7.30(\mathrm{~d}, 4 \mathrm{H}, 3 \mathrm{~J}=8.76 \mathrm{~Hz}), 7.09(\mathrm{~d}, 4 \mathrm{H}, J=$ $8.76 \mathrm{~Hz}), 6.78(\mathrm{dd}, 2 \mathrm{H}, 4 J=2.28 \mathrm{~Hz}, 3 \mathrm{~J}=8.17 \mathrm{~Hz}), 6.72(\mathrm{t}$, $1 \mathrm{H}, 4 J=2.1 \mathrm{~Hz}$ ); $\mathrm{UV} \mathrm{CHCl}_{3} \lambda_{\max } \mathrm{nm}(\mathrm{abs}): 416$ (0.218); IR $\mathrm{KBr} v \mathrm{~cm}^{-1}$ : 3727, 3432 broad, 1586, 1478; Anal. Calculated for $\mathrm{C}_{30} \mathrm{H}_{22} \mathrm{~N}_{4} \mathrm{O}_{2}$ (470.17): C, 76.58; $\mathrm{H}, 4.71 ; \mathrm{N}, 11.91 ; \mathrm{O}$, 6.80. Found C, 64.83; H, 4.43; N, 10.15 .

$\left(N, N^{\prime}\right)-4,4^{\prime}$ - (1,3-phenylenebis (oxy)) bis( $N$-(4-methoxybenzylidene)aniline) (17). Obtained as brownish crystalline solid and XRD [16] analysis were conducted; EIMS $\mathrm{m} / \mathrm{z}$ : 528; ${ }^{1} \mathrm{H}$ NMR $400 \mathrm{MHz}, \mathrm{CDCl}_{3} \delta$ (ppm): 8.38 (s, 2H), $7.84(\mathrm{~d}$, $4 \mathrm{H}, J=8.66 \mathrm{~Hz}), 7.2(\mathrm{~d}, 4 \mathrm{H}, J=8.71 \mathrm{~Hz}), 7.05(\mathrm{~d}, 4 \mathrm{H}, J$ $=8.70 \mathrm{~Hz}), 6.98(\mathrm{~d}, 4 \mathrm{H}, J=8.66 \mathrm{~Hz}), 6.73(\mathrm{dd}, 2 \mathrm{H}, 4 J=$ $2.1 \mathrm{~Hz}, 3 \mathrm{~J}=10.2 \mathrm{~Hz}), 6.69(\mathrm{t}, 1 \mathrm{H}), 3.86\left(\mathrm{~s}, 6 \mathrm{H},-\mathrm{OCH}_{3}\right)$; $\mathrm{UV} \mathrm{CHCl}_{3} \lambda_{\max } \mathrm{nm}$ (abs): 242 (0.08); IR KBr $v \mathrm{~cm}^{-1}: 3729$, 2958, 2839, 1685, 1602, 1507, 1253; Anal. Calculated for: $\mathrm{C}_{34} \mathrm{H}_{28} \mathrm{~N}_{2} \mathrm{O}_{4}$ (528.20): C, 77.25: H, 5.34: N, 5.30: O, 12.11: Found C, 73.26: H, 5.32: N, 5.38.

$\left(N, N^{\prime}\right)-4,4^{\prime}-(1,3-p h e n y l e n e b i s(o x y)) b i s(N-$ (4-nitrobenzylidene)aniline) (19). Obtained as red amorphous solid; EIMS $m / z: 558 ;{ }^{1} \mathrm{H}$ NMR $400 \mathrm{MHz}, \mathrm{CDCl}_{3} \delta(\mathrm{ppm}): 8.56(\mathrm{~s}, 2 \mathrm{H})$, $8.33(\mathrm{~d}, 4 \mathrm{H}, J=8.7 \mathrm{~Hz}), 8.01(\mathrm{~d}, 4 \mathrm{H}, J=8.7 \mathrm{~Hz}), 7.30$ (d, $4 \mathrm{H}$, $J=9 \mathrm{~Hz}), 7.09(\mathrm{~d}, 4 \mathrm{H}, J=9 \mathrm{~Hz}), 6.79(\mathrm{dd}, 2 \mathrm{H}, 2 J=2.7 \mathrm{~Hz}$, $3 J=8.1 \mathrm{~Hz}), 6.76(\mathrm{t}, 1 \mathrm{H}, J=2.1 \mathrm{~Hz}) ; \mathrm{UV} \mathrm{CHCl}_{3} \lambda_{\max } \mathrm{nm}$ (abs): 206 (1.53), 264 (1.72); IR KBr $v \mathrm{~cm}^{-1}: 3452$ broad, 3098, 2852, 1900, 1695, 1579, 1504, 1474; Anal. Calculated for $\mathrm{C}_{32} \mathrm{H}_{22} \mathrm{~N}_{4} \mathrm{O}_{6}$ (558.54): C, 68.81; $\mathrm{H}, 3.97 ; \mathrm{N}, 10.03 ; \mathrm{O}$, 17.19 Found C, 63.52; H, 3.97; N, 9.53.

\section{References}

[1] H. Schiff, "Mittheilungen aus dem universitätslaboratorium in Pisa: eine neue reihe organischer Basen," Annalen, vol. 131, pp. 118-119, 1864.

[2] N. E. Borisova, M. D. Reshetova, and Y. A. Ustynyuk, "Metalfree methods in the synthesis of macrocyclic Schiff bases," Chemical Reviews, vol. 107, no. 1, pp. 46-79, 2007.

[3] S. M. Nelson, "Developments in the synthesis and coordination chemistry of macrocyclic Schiff base ligands," Pure and Applied Chemistry, vol. 52, pp. 2461-2476, 1980.

[4] W. Radecka-Paryzek, V. Patroniak, and J. Lisowski, "Metal complexes of polyaza and polyoxaaza Schiff base macrocycles," Coordination Chemistry Reviews, vol. 249, pp. 2156-2175, 2005.
[5] S. R. Collinson and D. E. Fenton, "Metal complexes of bibracchial Schiff base macrocycles," Coordination Chemistry Reviews, vol. 148, pp. 19-40, 1996.

[6] U. Beckmann and S. Brooker, "Cobalt(II) complexes of pyridazine or triazole containing ligands: spin-state control," Coordination Chemistry Reviews, vol. 245, pp. 17-29, 2003.

[7] S. Brooker, "Complexes of thiophenolate-containing Schiffbase macrocycles and their amine analogues," Coordination Chemistry Reviews, vol. 222, pp. 33-56, 2001.

[8] S. Brooker, T. C. Davidson, S. J. Hay et al., "Doubly pyridazinebridged macrocyclic complexes of copper in $+1,+2$ and mixed valent oxidation states," Coordination Chemistry Reviews, vol. 216, pp. 3-30, 2001.

[9] S. Brooker, "Some copper and cobalt complexes of SchiffBase macrocycles containing pyridazine head units," European Journal of Inorganic Chemistry, vol. 2002, pp. 2535-2547, 2002.

[10] A. E. Martell, J. Perutka, and D. Kong, "Dinuclear metal complexes and ligands: stabilities and catalyticeffects," Coordination Chemistry Reviews, vol. 216, pp. 55-63, 2001.

[11] N. V. Gerbeleu, V. B. Arion, and J. Burgess, "2.9.1 Porphyrins and related compounds," in Template Synthesis of Macrocyclic Compounds, pp. 166-177, Wiley-VCH, Hoboken, NJ, USA, 2008.

[12] P. Guerriero, S. Tamburini, and P. A. Vigato, "From mononuclear to polynuclear macrocyclic or macroacyclic complexes," Coordination Chemistry Reviews, vol. 139, pp. 17-243, 1995.

[13] P. A. Vigato and S. Tamburini, "The challenge of cyclic and acyclic schiff bases and relatedderivatives," Coordination Chemistry Reviews, vol. 248, pp. 1717-2128, 2004.

[14] W. B. Callaway, J. M. Veauthier, and J. L. Sessler, "Schiffbase porphyrin and expanded porphyrin analogs," Journal of Porphyrins and Phthalocyanines, vol. 8, no. 1-3, pp. 1-25, 2004.

[15] K. Sonogashira, Y. Tohda, and N. Hagihara, "A convenient synthesis of acetylenes: catalytic substitutions of acetylenic hydrogen with bromoalkenes, iodoarenes and bromopyridines," Tetrahedron Letters, vol. 16, no. 50, pp. 4467-4470, 1975.

[16] S. Nadeem, M. R. Shah, and D. Vanderveer, "N,N'Bis(4-methoxy-benzyl-idene)-4,4' -(m-phenyl-enedi-oxy) dianiline," Acta Crystallographica E, vol. 65, no. 4, Article ID o897, 2009. 


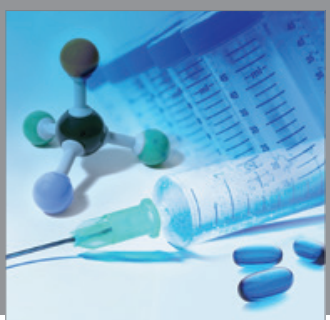

International Journal of

Medicinal Chemistry

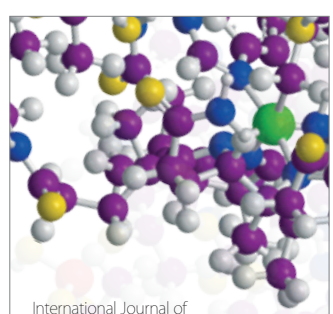

Carbohydrate Chemistry

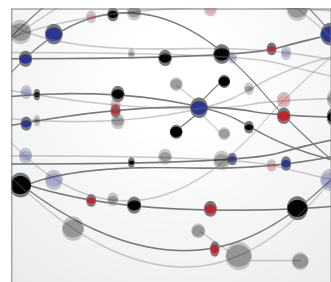

The Scientific World Journal
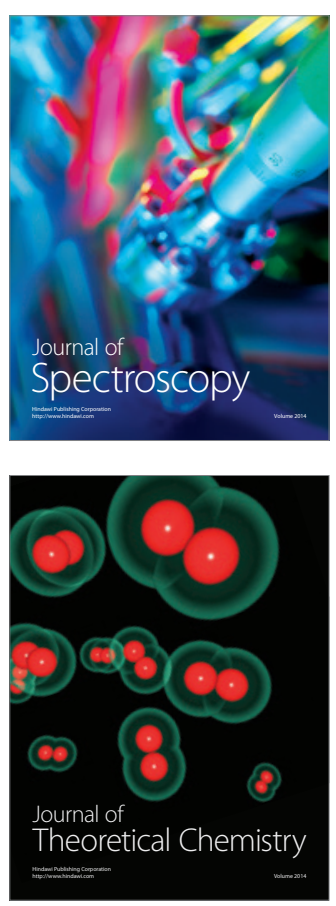
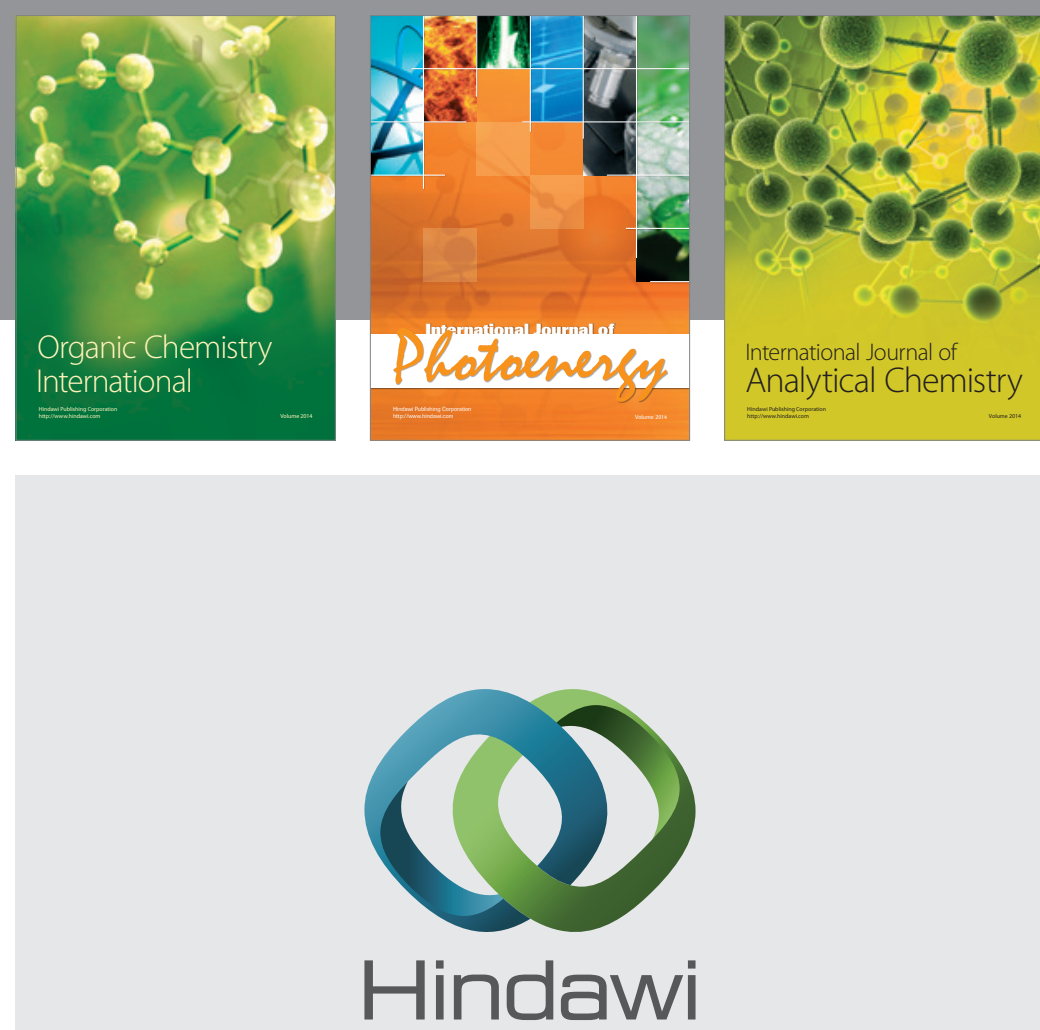

Submit your manuscripts at

http://www.hindawi.com
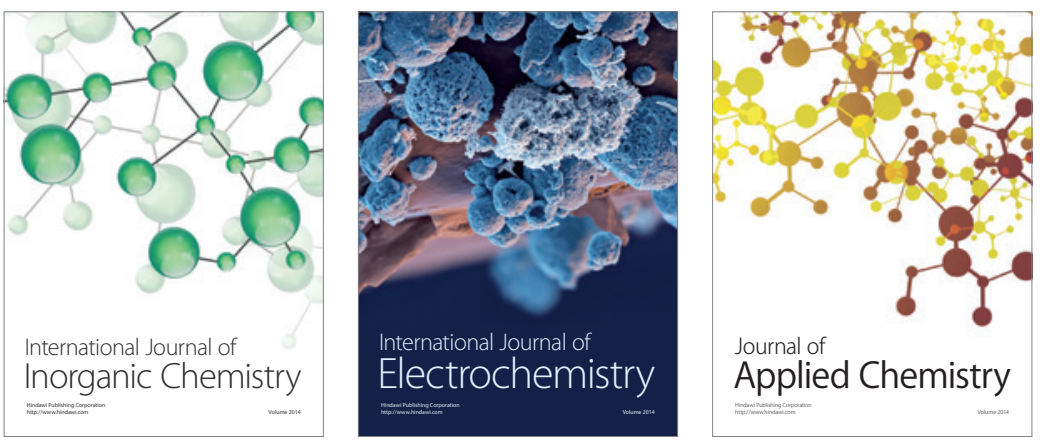

Journal of

Applied Chemistry
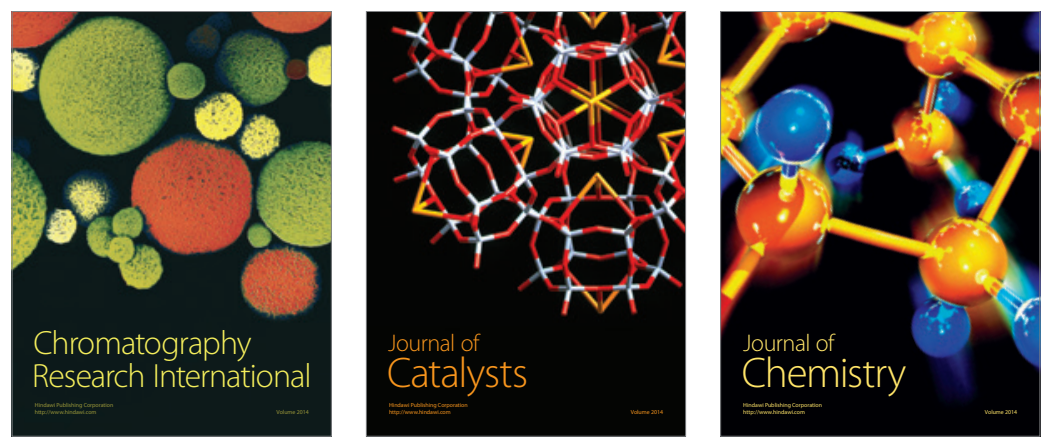
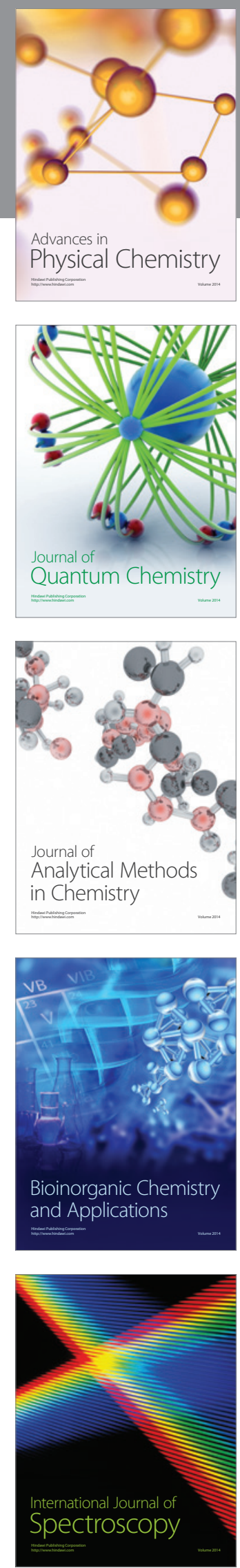